\title{
||||||||||||||||||||||||||||||||||||||||||||||||||||||||||. 125 Years of Diesel
}

Dear Reader,

On 27 February 1892, Rudolf Diesel registered a patent for a "new, rational heat engine” at the Imperial Patent Office in Berlin. In it, he described the concept of a heat engine based on the ideal cyclic process and defined the main features of the self-igniting engine in doing so, which was later named after him. In his day, critics were sceptical as to whether the technical implementation would ever succeed - the high pressure in particular was considered unmanageable. However, this was necessary to be able to compress the air-fuel mixture to such a degree as to facilitate self-ignition a guarantee for maximum efficiency and Diesel's goal. 1897 saw the first functional model of this engine reach completion. It ran with what was then an unthinkable efficiency of 26.2 percent. At the world exhibition in Paris in 1900, the diesel engine was awarded the Grand Prix. However, a few more years elapsed before the diesel really got up to speed. The first seafaring diesel motor vessel set sail from the shipyard in 1912, while the first diesel locomotive also emerged the same year. Rudolf Diesel himself didn't live to witness the ensuing triumph of his invention; he died in 1913 under unexplained circumstances.

Today, the diesel engine is an established presence: robust and efficient. It transports people and goods, is used in construction and agricultural machines and provides global wealth and progress. Critics bemoan its emissions, but have to concede that it will be hard to imagine our lives without this engine for some considerable time to come. This also reaffirms the crucial need to continue refining the diesel engine to generate low emissions and earn wider acceptance - in the political arena above all. I am certain that this is also what Rudolf Diesel would have wanted. In our cover story, we have collected some examples of how the engine industry is shaping the future of the diesel engine.
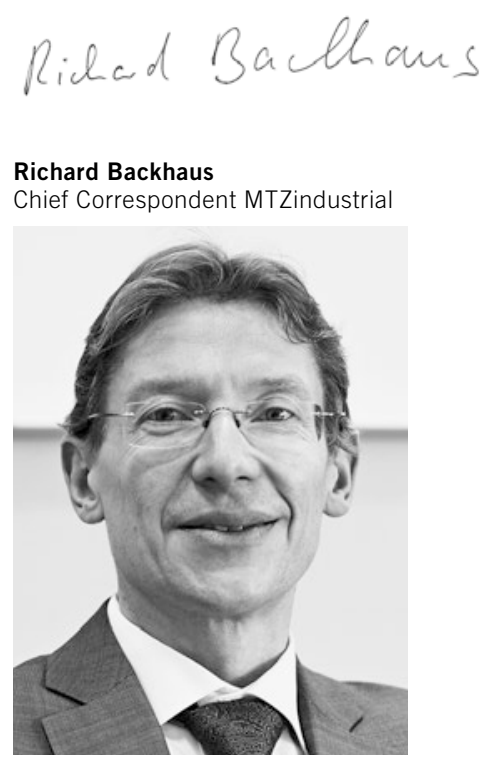